\title{
Post-traumatic stress disorder as a risk factor for dementia: systematic review and meta-analysis - ERRATUM
}

Mia Maria Günak, Jo Billings, Emily Carratu, Natalie L. Marchant, Graziella Favarato and Vasiliki Orgeta

\section{Keywords}

Post-traumatic stress disorder; dementia; risk; systematic review; meta-analysis.

\section{Copyright and usage}

(c) The Authors 2021. Published by Cambridge University Press on behalf of the Royal College of Psychiatrists. https://doi.org/10.1192/bjp.2020.150 Published online by Cambridge University Press, 16 September 2020
Mia Maria Günak; Jo Billings; Emily Carratu; Natalie L. Marchant Graziella Favarato; Vasiliki Orgeta

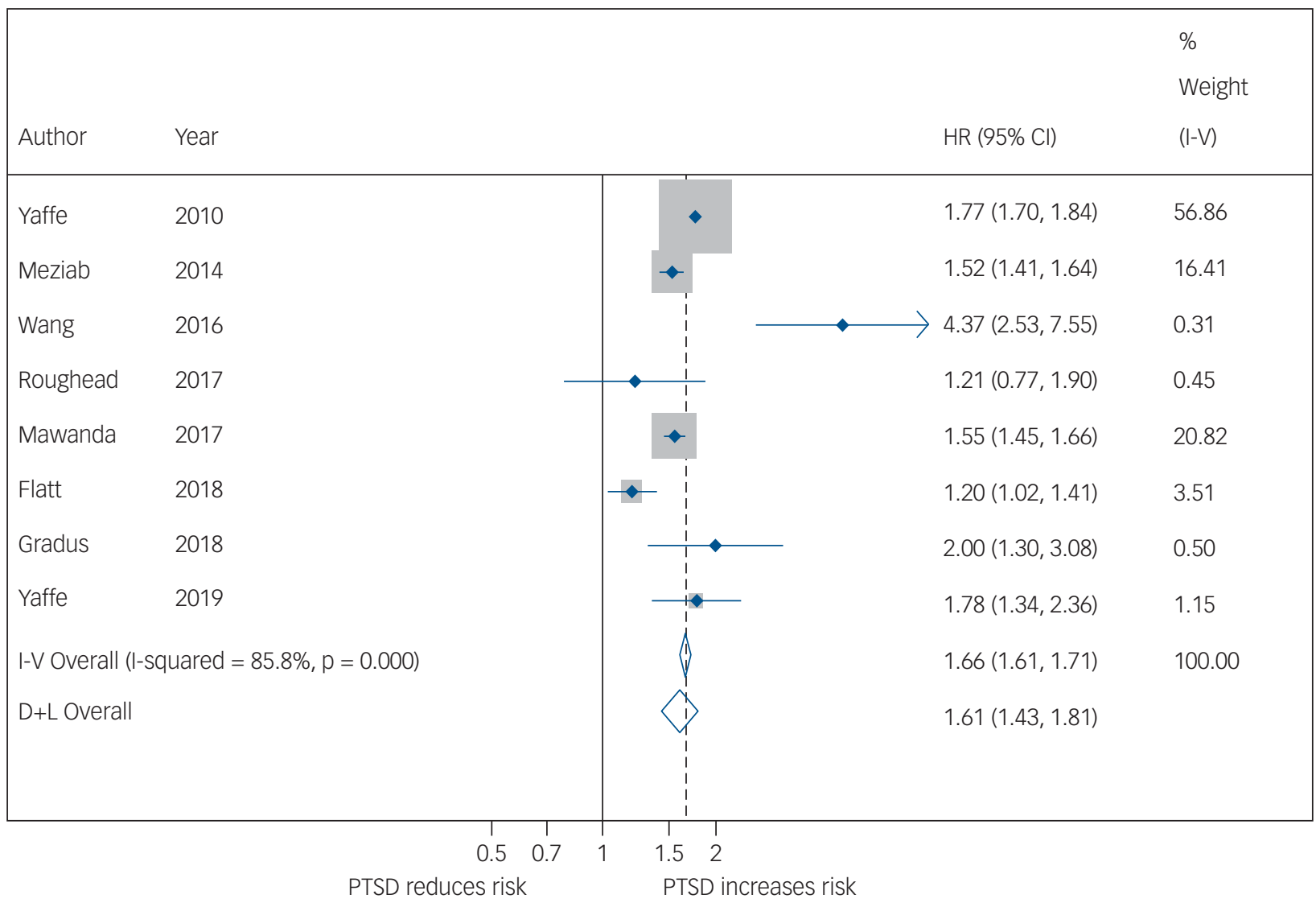

\section{Fig. 2 Meta-analysis of hazard ratios of post-traumatic stress disorder (PTSD) compared with no PTSD on risk of dementia.}

In the published version of the above article, Figure 2 was reproduced with several errors and omissions. The correct original version is shown below. The publisher apologises for the error.

\section{Reference}

Günak MM, Billings J, Carratu E, Marchant NL, Favarato G, and Orgeta V. Post-traumatic stress disorder as a risk factor for dementia: systematic review and metaanalysis. Br J Psychiatry 2020. https://doi.org/10.1192/bjp.2020.150. 